\title{
直交磁心形 $\mathrm{dc}-\mathrm{ac}$ 変換器の三相化に関する検討
}

\author{
Orthogonal-Core Type Three-Phase dc-ac Converter \\ 一一倉 理・斎藤寛礼・田島克文* ・秦泉寺敏正 \\ 東北大学工学部，仙台市青葉区荒巻字青葉 (雨980) \\ *秋田大学鉱山学部, 秋田市手手形学園町 1-1 (画010) \\ O. Ichinokura, H. Saito, K. Tajima* and T. Jinzenji \\ Faculty of Engng., Tohoku Univ., Aoba, Aramaki, Aoba-ku, Sendai 980 \\ *Mining College, Akita Univ., 1-1, Tegata-Gakuencho, Akita 010
}

In a previous paper, the authors proposed the orthogonal-core type dc-ac converter for photovoltaic power system. The dc-ac converter has desirable features including simple construction, high security and easiness of maintenance. The operating characteristics of the single-phase converter for residential photovoltaic power system have been reported. In this paper, we discuss the fundamental operations of the orthogonal-core type dc-ac converter for three-phase power system based on simulations and experiments. Desirable construction of the orthogonal-core type three-phase dc-ac converter has been clarified.

Key words: orthognal-core, dc-ac converter, threephase, photovoltaic system

\section{1.まえがき}

連系方式の太陽光発電システムは, 商用電源をバック アップよすることにより，太陽電池による不規則な発生 電力の有効利用をはかる6ので，オイルショックを契機 として，自然エネルギーの利用技術の一方式として開発 研究が進められてきだー8). 近年は地球温暖化防止の理 由から，太陽光発電システムへの要請が高まっておら，

今後，民生あるいは産業用として太陽光発電システムの 導入は進むものと考えられる。

筆者らの考案による直交磁心形 $\mathrm{dc}-\mathrm{ac}$ 変換器は, 太陽 電池などの不規則なローカルエネルギー源と既存の交流 系統を簡単かつ安全に結ぶことが可能であるため, 連系 方式の太陽光発電システム用 $\mathrm{dc}-\mathrm{ac}$ 変換器としての用

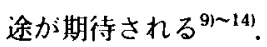

これまで筆者らは，主として家庭用規模の太陽光発電 システムに適用することを前提とし，単相用の直交磁心 形 $\mathrm{dc}-\mathrm{ac}$ 変換器について検討を行ってきた。ここでは, 直交磁心形 $\mathrm{dc}-\mathrm{ac}$ 变換器の適用範囲の拡大を目的とし て，本変換器の三相化について基礎的検討を行った。す
なわち, 直交磁心の二相結線時の特性について, シミュ レーションならびに寒験の両面から種々検討を行った。 その結果, 三相結線法の違いによる变換器特性の差翼な ど，三相化を進める際に必要な基礎的事項が明らかに なった。

本論文はこれらの成果について述べるものである.

\section{2. 磁心形状ならびに回路權成}

直交磁心としてはこれまで，Fig.1(a) に示す 2 重直父 磁心と同図 (b) に示す U 形直交磁心が提案されている. 図中の $N_{1}, N_{2}$ は一次および ...次巻線, $i_{1}, i_{2}$ は一次およ び二次電流， $\phi_{1}, \phi_{2}$ は一次および二次磁束を示している.

Fig. 2 に三相用の直交磁心形 $\mathrm{dc}-\mathrm{ac}$ 変換器の回路構 成を示す.プッシュプル接続された 3 組の直交磁心の一 次側は三相結線され，三相方形波インバータによって氻 磁されている，二次側も同椂に三相結線され，既存の： 相交流系統に接続されている.

Fig. 2 は一次側が $Y$ 結線, 二次側が $\Delta$ 結線の例であ るが，結線法の組み合わせとしては，このほかに $\Delta-\Delta$, $\Delta-\mathrm{Y}, \mathrm{Y}-\mathrm{Y}$ が考えられる. 以下, これらの結線法の違い による特性の差異についてシミュレーションならびに尖 験を行った結果について述べる.

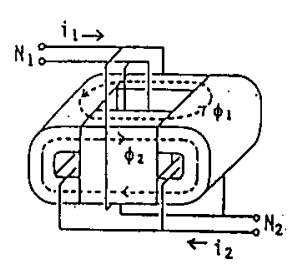

(a)

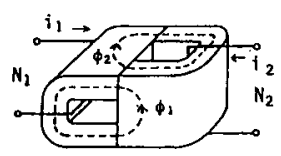

(b)
Fig. 1 Schematic diagram of the orthogonalcore. (a) Two orthogonal-flux type. (b) Two C-core type. 


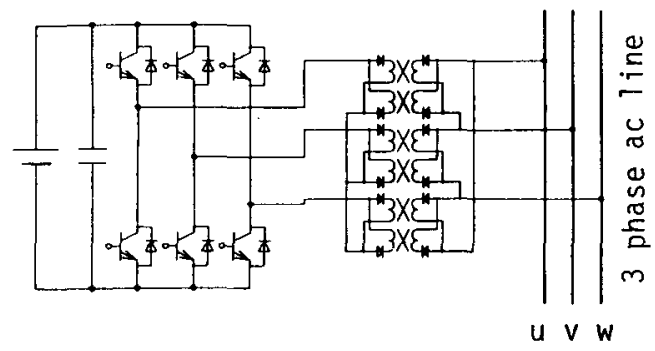

Fig. 2 Basic circuit of the orthogonal-core type three-phase dc-ac converter.

\section{3. シミュレーション}

\section{1 尌筆方法}

ここではシミュレーションに基づき，三相結線方式に よる特性の差異について検討を行う，計算には，汎用の [川路シミュレーションのッールである SPICE を用いた。 Fig. 3 にシミュレーションに使用した直交磁心の

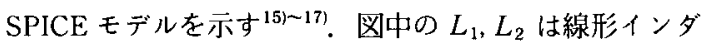
クタンスであり， $L_{1}$ を流れる電流 $i_{10}$ は一次の磁心磁束 に， $L_{2}$ を流れる電流 $i_{20}$ は二次の磁心磁束に比例するす のである. $F_{1}, F_{2}$ はいずれも電流 $i_{10}$ 上 $i_{20}$ 双方により制 御される非線形従属電流源であり，これにより直交磁心 の一次と二次の相互作用を表現している， $R_{1}, R_{2}$ は一次 および二次巻線抵抗である。なお，先に報告した SPICE モデルにおいては，鉄損の影響むある程度考慮したが， ここでは出力電流歪みと力率に主眼をおくこととし，こ れらの特性は直交磁心の磁化特性でほぼ決定されること から，鉄損は無視した。

Fig. 4 は, 三相結線時の特性算定のための計算モデル である. 簡単のため三相インバー夕の代わりに方形波電 尼源を使用した。同図において, 直交磁心の一相当たり の一次および二次電压 $e_{1}, e_{2}$, , 一次および二次電流 $i_{1}, i_{2}$. さらに二次側の線電流 $i_{\mathrm{u}}$ を計算し, 次式に基づいて一相 当たりの一次および一次電力 $P_{1}, P_{2}$,ならびに二次線電 流実効值 $I$ を求める。
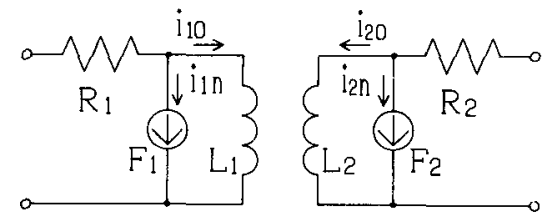

Fig. 3 Numerical model of the orthogonal-core used in the SPICE simulation.

$$
\begin{aligned}
& P_{1}=(1 / T) \int_{0}^{T} e_{1} \cdot i_{1} \mathrm{~d} t \\
& P_{2}=-(1 / T) \int_{0}^{T} e_{2} \cdot i_{2} \mathrm{~d} t \quad[\mathrm{~W}] \\
& I=\sqrt{(1 / T) \int_{0}^{T} i_{\mathrm{u}}^{2} \mathrm{~d} t}
\end{aligned}
$$

これらの結果から，次式により，効㻭 $\eta$ および出力側 からみた実効的な力率入を計算した。

$$
\begin{array}{ll}
\eta=\left(P_{2} / P_{1}\right) \times 100 & {[\%]} \\
\lambda=\left(3 P_{2} / \sqrt{3} E I\right) \times 100 & {[\%]}
\end{array}
$$

ここで $E$ は二次線間電圧実効值である.また出力電流 歪み率は，上記の線電流 $i_{\mathrm{u}}$ の高調波成分を高速フーリエ

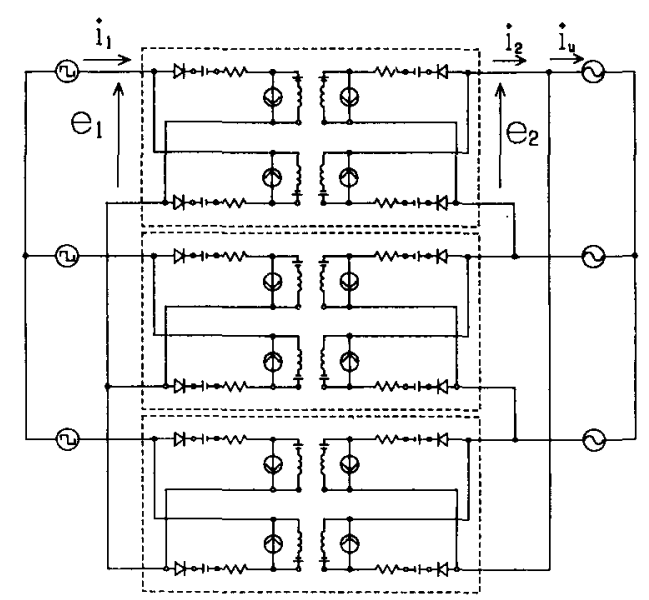

Fig. 4 SPICE implementation of the orthogonal-core type three-phase $\mathrm{dc}-\mathrm{ac}$ converter.

Table 1 Dimensions of the core and number of turns in the windings of the orthogonal-core used in the simulation

\begin{tabular}{l|l}
\hline \multicolumn{2}{c}{ Two or thogonal $-f$ lux type } \\
\hline Dimension (mm) & $a=25, b=40, c=42, d=85, e=90, g=25, h=100$ \\
\hline Hinding (turns) & $N_{1}=200, \quad N_{2}=200$ \\
\hline
\end{tabular}
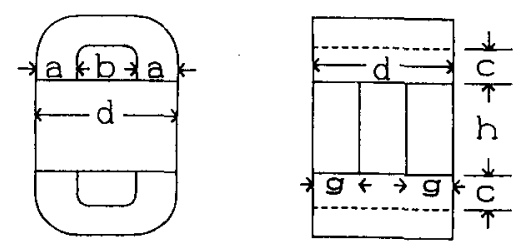

日本伈用磁気学会誌 Vol. 16, No. 2, 1992 
変換により求め, 21 次の高調波成分まで考慮して計算 した.

\section{2 計算结果}

シミュレーションには，先に報告した文献 16 で使用 した 2 重直交磁心を用いた. Table 1 にその諸元を示 す. 本磁心の計算モデルの具体的な回路定数は文献 16 を参照されたい.

計算における電源電圧值は，結線法にかかわらず，一 相当たりの最大出力が単相の場合と等しくなるように選 んだ. Table 2 に計算の際に設定した一次および二次の 線間電王実効值を示す。

Fig. 5 に出力電流歪み率対出力特性を示す. 図中には 比較のため単相の場合の特性む示した，横軸は一相当た りの最大出力 $P_{2 \mathrm{~m}}$ に対する出力 $P_{2}$ の比で示した。 これ をみると，単相と比較して三相では，いずれの結線にお いても出力電流歪みは效善される。これは $\Delta$ 結線の場 命，直交磁心の二次電流 $i_{2}$ に含まれる第 3 調波成分は $\Delta$ 結線内を還流するため線電流には現れないこと，Y 結線

Table 2 Operating voltages used in the simulations

\begin{tabular}{|c|c|c|c|}
\hline \multirow{2}{*}{ Connection } & \multicolumn{2}{|c|}{ Line vol tage $(\mathbb{Y})$} & \multirow{2}{*}{$\begin{array}{c}\text { Output porer } \\
\text { (I/phase) }\end{array}$} \\
\cline { 2 - 3 } & priary & secondary & \\
\hline$\Delta-\Delta$ & 131.7 & 100 & 444.1 \\
\hline$\Delta-Y$ & 126.1 & 173.2 & 445.2 \\
\hline$Y-\Delta$ & 203.6 & 100 & 445.4 \\
\hline$Y-Y$ & 213.8 & 173.2 & 444.1 \\
\hline I phase & 100 & 100 & 446.6 \\
\hline
\end{tabular}

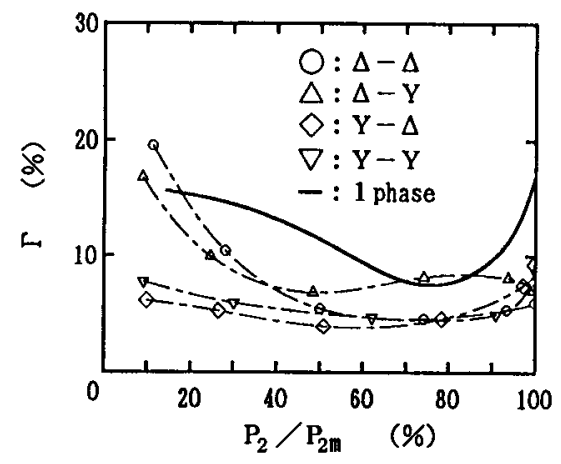

Fig. 5 Simulation results of the variations of the distortion factor of the output currents.
においては，中性点が接地されていない場合、線電流に は第 3 調波成分が流れ得ないことに起因すると考えら

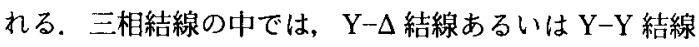
の場合の低減効果が大きいことがわかる.

Fig. 6 に力率対出力特性を示す。これをみると，二相 の場合の力率は単相と比較しておおむ欢善される傾问 にある。これは出力電流歪み率と同様に線電流中に第 3 調波成分が現れないことに起因すると考えられる，各結 線方式で比較すると， $\Delta-\Delta$ 結線および $\mathrm{Y}-\mathrm{Y}$ 結線の場合 の力率が比較的良好であることが認められる。

Fig. 7 に効率を示す. 同図の上うに, 三相結線時の効 率は，Y-Y 結線において，広い動作範囲にわたり，若 † の改善が認められているものの, 全体としては単相の場 合と大きな差異は認められなかった。

\section{4. 実}

3 章の結果に基づき，ここでは実験的検討を行った。 実験においては，実規模の装置における特性の検訴を日 的とし，磁心としては製作および組み立ての比較的容易 なU形直交磁心を用いた。 Table 3 に, 実験に用いた磁 心法および巻数を示す。本磁心の最大出力は， $1 \mathrm{~kW}$ 程度である。

Fig. 8(a)に，これらの直交磁心で構成した 3 組の问路 の単相における電力変換特性を示す，同図 (b)には各相 の歪み率, 力率, 効率対出力の関係を示す。これらの図 に示すように，変換電力は 3 組の回路で差異が認められ るが，歪み率，力率および効率については，ほぼ同様の 特性を示していることがわかる．以下に述べる三相結線 時との比較には 3 組の中で平均的な特性を示した $\mathrm{V}$ 相 のものを使用した。

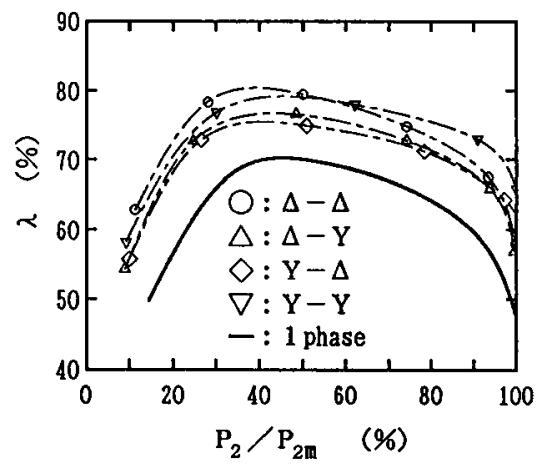

Fig. 6 Simulation results of the relations between the output power factor and output power. 


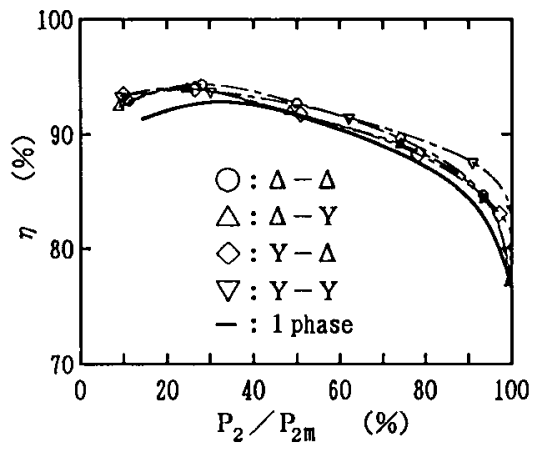

Fig. 7 Simulation results of the relations between the efficiency and output power.

Table 3 Dimensions of the core and number of turns in the windings of the orthogonal-core used in the experiments.

Two c-core type

\begin{tabular}{l|c}
\hline $\operatorname{Dimension}(\mathrm{mm})$ & $\mathrm{a}=35, \mathrm{~b}=35, \mathrm{c}=42, \mathrm{~d}=105$ \\
\hline Winding(turns) & $N_{1}=400, \quad N_{2}=200$ \\
\hline
\end{tabular}
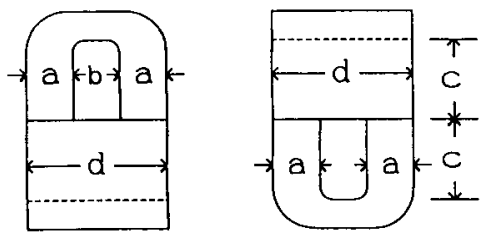

:相結線時の動作電圧は，シミュレーションと同様, それぞれの結線における最大出力が一致するように選ん だ（実験においては二相全出力で約 $3 \mathrm{~kW}$ となるように 選んだ). Table 4 に実験の際に設定した一次抢よび二 次の線間電圧実効值を示す.

Fig. 9 に出力電流歪み渂対出力特性を示す。実験にお ける $P_{2}$ および $P_{2 \mathrm{~m}}$ は，三相の場合には三相全出力を 3 で割った平均值を使用した、これをみると，いずれの結 線方式に打いても, 出力電流歪みは単相と比較して改善

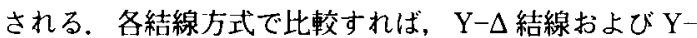
Y 結線の場合において歪み率が小さいことがわかる。こ の傾向は, シミュレーション結果と一致する.

Fig. 10 に力率対出力特性を示す.これをみると、シ ミュレーション結果にみられたように，三相結線時には

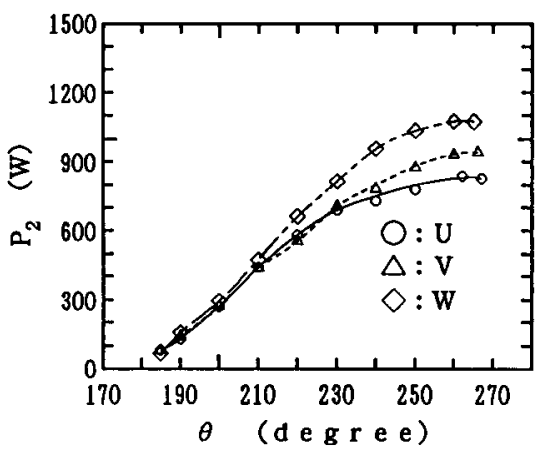

(a)

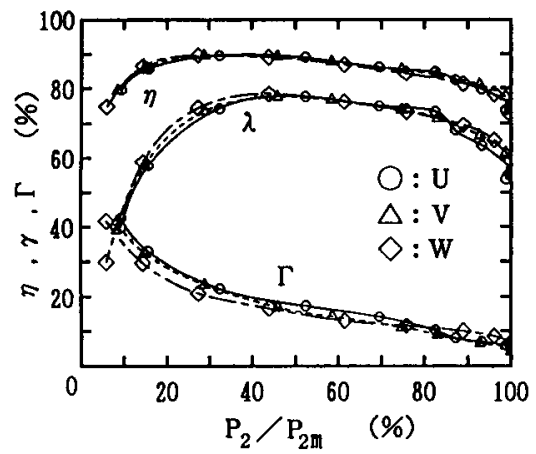

(b)

Fig. 8 Power conversion characteristics measured in the orthogonal-cores used in the experiments. (a) Power versus phase angle relations. (b) Efficiency, power factor and distortion factor of the output currents.

Table 4 Operating voltages used in the experiments

\begin{tabular}{|c|c|c|c|}
\hline \multirow{2}{*}{ Connection } & \multicolumn{2}{|c|}{ Line voltage (Y) } & \multirow{2}{*}{ Output porer $(\mathbf{K})$} \\
\cline { 2 - 4 } & prinary & secondary & \\
\hline$\Delta-\Delta$ & 205 & 100 & 2.97 \\
\hline$\Delta-Y$ & 200 & 173.2 & 2.91 \\
\hline$Y-\Delta$ & 335 & 100 & 3.02 \\
\hline$Y-Y$ & 340 & 173.2 & 3.05 \\
\hline
\end{tabular}

力率が単相と比較して改善される傾向が認められる。奏

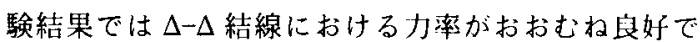
あった.

Fig. 11 に効率を示す. 闹図をみると,シミュレーショ ン結果上実験結果は，その倾向において大略一致する 


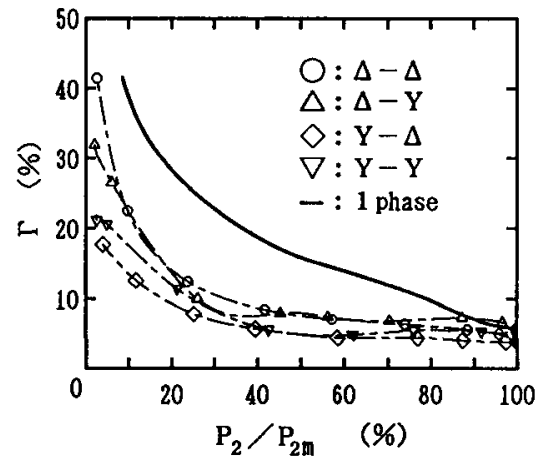

Fig. 9 Distortion factor of the output line currents of the three-phase orthogonal-core type dc - ac converter.

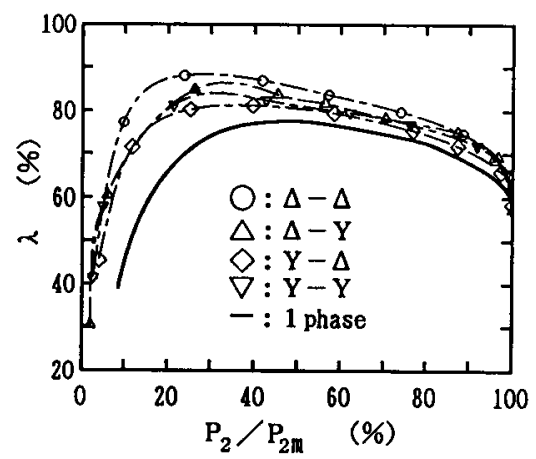

Fig. 10 Output power factor of the orthogonalcore type three-phase $\mathrm{dc}-\mathrm{ac}$ converter.

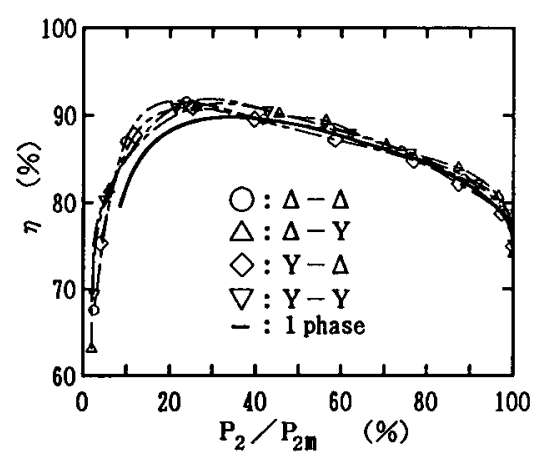

Fig. 11 Efficiency of the orthogonal-core type three-phase $\mathrm{dc}-\mathrm{ac}$ converter.

が，実験結果によると，結線方式の違いによる効率の差 異は余り認奻られなかった。

これらの実験結果と 3 章のシミュレーション結果を 比較した場合、シミュレーションと実験に使用した直交 磁心の形状が異なること、シミュレーションにおいては
直交磁心の磁化特性を磁束の 5 次式で近似しているが， 実際の直交磁心の磁化特性を不飽和・飽和領域ともに高 精度に近似するためにはより高次の項まで考㦄する必要 があること，奏験においては，使用した 6 個の直交磁心 の特性が不均一であることなどの理由から，定量的には 差異か認められるが，定性的には大略一致していると考 えられる.したがって, 直交磁心形 $\mathrm{dc}-\mathrm{ac}$ 変換器の：相 化を図る場合の結線法としては, Y-Y 結線が比較的望 ましいと考えられる。

\section{5. まとめ}

以上，直交磁心の三相化について，特に結線方式の違 いによる特性の差異について，シミュレーションと実験 の両面から種々検討を行った。シミュレーション結果よ 実験結果はほぼ同様の傾向を示した。：三相之単相を比較 すれば，効摔については大きな差異はないと思われる が, 出力電流歪みおよび力率は三相結線した方が改善さ れる. 各結線方式で比較した場合，総合的にみると，YY 結線の場合において比較的良好な特性が得られるこ とが明らかになった。

今後の課題としては，最適設計を目的としたシミュ レーション精度の向上と, 実用化のためには装置のコン パクト化を図る必要がある，さらに特性面だけではなく 実系統に即した結線方式と保護方式の検討む必要之考元 られる.これらの事項については現在検討中である.

\section{文献}

1)武田: 電気学会論文誌, 102, 1132 (1982).

2) 関，小川，赤尾，矢崎：電気学会講演論文集，No. 528 (1985).

3) 原島, 稲葉, 高島: 電気学会講演論文集, No. 531 (1985).

4）北村，小川，後長，日和，大嶋，佐野：電気学会講演論义 集, No. 534 (1985).

5) 高橋, 板井, 細川, 武田：電気学会講演論文集, No.1185 (1985).

6) 斎藤, 檜垣：電気学会講演論文集, No. 511 (1986).

7) 凧, 国吉, 北條, 安田：電気学会講演論文集，No. 1203 (1987).

8) 白石, 萩原, 徳田, 松川, 栗毛: 電気学会講演論文集, No. 1204 (1987).

9) 一/倉, 前田, 高橋, 村上：日本応用磁気学会誌，10,351 (1986).

10) 一八會, 上野, 前田, 高橋, 村上：日本応用磁気学会誌, 11. 355 (1987).

11) 一/倉, 前田, 高橋, 村上: 電気学会論文誌, 107-D, 1507 (1987).

12) 一/倉, 前田, 三田村, 高橋, 村上: 電気学会論文誌, 108D. 151 (1988).

13）一，倉，田島，村上：日本応用磁気学会誌，12,355 (1988).

14) O. Ichinokura, M. Maeda, H. Takahashi and K. Mura- 
kami: IEEE Trans. Magn.. 24, 1969 (1988).

15) 恢藤, 时島, 一八倉, 秦泉寺: 電子情報通信学会技術研究 報告，90(199)，23 (1990)。

16）佐藤，一，倉，田島，秦泉寺：日本応用磁気学会誌， 15 , 513 (1991).
17) O. Ichinokura, K. Sato, K. Tajima and T. Jinzenji: $J$. Appl. Phys., 69, 4928 (1991).

1991 年 11 月 12 日受理, 1992 年 1 月 30 日採録 